\title{
The Brazilian Program of Educational Development for Permanent in- Service Education
}

\author{
Andressa Andrieli do Carmo \\ State University of Londrina \\ Brazil
}

\begin{abstract}
The Brazilian State Secretariat for Education (SEED) developed, in 2007, the Program of Educational Development of Paraná State (PDE-PR) aiming to improve the quality of education. In order to make this project concrete, the participants are advised by tutors of one of the 14 Public Higher Education Institutions of Paraná (IPES) that became partners of the program. Among them is the State University of Maringá (UEM) which oriented 38 English teachers of public schools in 2007 and 2008. The aim of this research was to verify the continuity of the projects developed by these teachers, their main motivations to participate on an in-service education process, and the tutors' perspective related to the aptitude of participants to develop a pedagogical proposal. The contribution of PDE to the teachers of public schools was determined, as well as its positive and negative aspects. The results show that almost one third of these teachers no longer work as teachers; and that their main motivations to participate on PDE are related to their self personal and professional improvement. They also highlighted how impractical it is to apply the activities they develop during the program, which leads us to think that the reality of the schools they work at is not the same reality the mentors of the PDE program perceive in Paraná State in Brazil.
\end{abstract}

\section{Introduction}

Schools are places where students can build their knowledge and that have the social function of transforming them in reflexive and critical beings. And teachers are those who play the role of tutors in this transformation, mainly in public schools in Brazil, where there are bigger challenges to be daily overcome. These difficulties are reflected in the innumerous critiques on the Brazilian educational system made by researchers and studious people and "the learning difficulties presented by students because of a teaching system 'evaluated' as nonqualified" [1]. Despite the critiques mainly range the school institutions, teachers are inserted in this system and the responsibility for the bad quality of pedagogical practices is implicitly attributed to them.
The educational problem lies, then, on the performance of teachers and on their specific role of teaching. However, to evaluate the results obtained in the classroom, the direct reflexes of their knowledge - shaped since their initial education must also be considered. And teachers, like every professional (if not the main one), should not be limited to the stagnation of the education they have received. It is necessary to promote a qualitative revolution in the educational field which requires investments in the qualification of teachers and in pedagogical projects [1]. Thus, this action may be considered essential for the success of the educational system, once the job of a teacher must not only be done in order to transmit information, but also, to transform the reality they are part of.

In this context, the State Secretariat for Education (SEED) developed, in 2007, the Program of Educational Development of Paraná (PDE-PR) aiming to improve the quality of education in the Paraná State. The program has provided the teachers of the public schools with the opportunity to dedicate themselves exclusively to their education, because "It is incontestable that the performance of a well prepared teacher has direct influence in a better learning process of students" [2].

After a great workload complemented with courses related to education and specific areas, these professionals have to develop a pedagogical proposal which should be applied in the schools they work at, in order to contribute to a better school performance of their students and future classes. In order to make this project concrete, the participants are advised by tutors of one of the 14 Public Higher Education Institutions of Paraná (IPES) that became partners of the program. Following the guidelines of PDE, it is expected that the pedagogical schoolbooks developed during the program are incorporated to the teachers` daily routine, regardless the classes which are being taught (i.e. they are supposed to be used continuously even after the end of the teachers training).

Through the effective establishment of these new practices, a successful learning by students is expected to be reached and, consequently, the success of teachers. Based on an in-service 
education, PDE must not be understood as a compensatory measure, but as a continuous educational policy, with pedagogical dimensions which prioritize a true reformation in the school quality.

With its fourth class in course, PDE awakens the interest of researchers who aim to analyze the program guidelines and the possible contributions to overcome the challenges teachers face in the schools systems they are part of. The investigation of such program is of extreme relevance to the evaluation of its effectiveness as a policy of in-service education for English teachers of public schools not only in Brazil, but as a model to be followed by other countries as well.

\section{Literature review}

The State Secretariat for Education (SEED) has the valorization of education professionals and a democratic, participative and collegiate school management as principles. Based on these basics, and aiming to improve the quality of education, it has developed the PDE - Program of Educational Development of Paraná.

Started in 2007, jointly with the State Secretariat for Science, Technology and Higher Education of Paraná (SETI), the program has the main purpose of providing the state public schools teachers, theoretical-practical support to develop educational projects, "but also promote the professional valorization of teachers creating material and pedagogical conditions for their qualification and advances in the professorship career plan" [3].

A partnership was established with 14 Public Higher Education Institutions of Paraná (IPES) which offer advising to the regular teachers of public schools who join the program. They are:

- EMBAP - Music and Fine Arts School of Paraná;

- $\quad$ FAFIPA - State College of Education, Sciences and Language, Linguistics and Literature of Paranavaí;

- $\quad$ FAFIPAR - State College of Philosophy, Sciences and Language, Linguistics and Literature of Paranaguá;

- $\quad$ FAFI-UV -State College of Philosophy, Sciences and Language, Linguistics and Literature of União da Vitória;

- $\quad$ FECILCAM -State College of Sciences and Language, Linguistics and Literature of Campo Mourão;

- $\quad$ FAP - Arts College of Paraná;

- UEL - State University of Londrina;

- UEM - State University of Maringá;
- UENP - State University of the North of Paraná;

- UEPG - State University of Ponta Grossa;

- $\quad$ UFPR - Federal University of Paraná;

- UNICENTRO - State University of the Middle West; UNIOESTE - State University of the West;

- $\quad$ UTFPR - Technological Federal University of Paraná.

The teachers who are allowed to participate in the program must be in Level II, Class 11 of the State Career Plan (Law 103/2004)4. This law, published in the Official Diary number 6687 in 15th of March, 2004, defines the following terms:

Level: the division of the teachers `areer according to their schooling degree, entitling or certification of the educational development program.

Class: division of each level in units of functional progression.

Teacher: civil servant who practices teaching, pedagogical support, headship, coordination, advisement, supervision, counseling, planning and research in educational institutions, regional educational centers, state secretariats of education and units linked to them.

It also states that the career of the basic education teachers is structured in six levels, being each of them composed by 11 classes. According to this Carrer Plan, the teachers who are in Level II are those who currently occupy the position of teachers and education specialists in the State Schools of Paraná. Thus, in the beginning of the program, they have $100 \%$ of their working activities suspended in the first year, and $25 \%$ of them in the second year. During this process, there is a great workload which must be accomplished with courses related to education, technological education and specific areas.

They have a great financial cost for their execution, so these teachers receive financial support from SEED for trip, feeding and housing expenses, with no discounts on their income, being substituted in the schools during the program. Concomitant to that, a project must be developed to be implemented in the school with the advising of a tutor - master or doctor - of one of the High Education Institutions which are partners of the program. This project must be developed parallel to a scientific article which must be presented in the end of the program.

Other activities which are part of the PDE teachers' in-service education are: congresses, 
symposiums, written works, discussions, seminars, among others. These activities are developed after the basic education, made through their teaching career. They are activities developed by working teachers with an educational goal, made individually or in group, aiming the personal and professional development [4]. This education is also conceptualized [2] as a planned proposal which aims to change the educators through a reflexive, critical and creative process, motivating them to produce knowledge and to interfere in reality.

In the present and virtual modalities, PDE teachers must be the real responsible ones to surpass the traditional limits of education in the program. PDE has a pedagogical proposal which confronts the homogeneous, discontinuous and fragmented inservice education, centralized in the pedagogical practices in a reflexive way [5]. Thus, to interfere in the school reality, teachers must elaborate a textbook, workbook or other material which is going to be used pedagogically by students and teachers of the public state education.

This implementation is made on the advising of one of the tutors of IPES, who will also help them in elaborating a scientific article which will report the process of development of their work and the results of the intervention. Choosing such proposals, teachers must have criteria and care which can favor formation situations and, mainly, implement new practices which can understand the real needs of their job, making the development of all the students possible [4].

It is important to emphasize the school processes can only be understood in the widest social relations [2], like they are in schools - where the meaning of politics is learned - once their sense is explicated when the practices need to be modified. Because of this, It is hoped that the procedures proposed by the teachers can be used in any situation, not only with those groups who are part of this program, i.e. it is hoped that the teachers are able to apply these innovations to their daily routine, no matter what classes are given to them.

Every production is made public by the program and displayed in the PDE/PR website, and the materials are exposed in the libraries of the participant schools through a summary catalog, which is still being built. Because it is a recent program, only in the last two years it is possible to notice the publication of scientific works about this theme. Some works have been published by the National Association of Post-Graduation and Research in Education (ANPED) about in-service education and other subjects related to PDE. Because it is intended to improve the performance of the teacher in the classroom, aiming a better performance of the students, this program can be defined as a planned, implemented pedagogical intervention that proposes significant changes to the teachers' way of thinking. This way of thinking can develop the involvement and compromise of teachers to establish new practices which can make students have a better learning and, consequently, a better result for teachers.

If there are resources for the Brazilian education there will be conditions to adequately equip schools and give them teachers with education obtained in long term courses [6]. Thus, it is expected that the pedagogical innovations of these teachers are not limited to this specific program, but are effectively put in practice in the way they work. Because teachers have already gotten a built experience and everything new must be incorporated to this background knowledge, when there is something new to be presented to them, they have to face a lack of balance while processing all the information they have received. Doing so, they must have been given some time to submit to what is considered new, and put it in practice to be used as a new incorporation study [2].

For all these reasons are taken as a priority in the in-service education, it is relevant to investigate the effects or consequences of a program like PDE after it was implemented. The current work of teachers who participated in the beginning of this program (2007-2008) can make the analysis of the adaptation of pedagogical practices possible, and then researches and participants may ask themselves what the changes in the teachers' performance are and what happens to them after some time of their implementation.

It is the teacher who transforms the innovation idea in a pedagogical innovator action [2]. If he or she is motivated to act in a different way of what he or she is used to, depending on a great effort and dedication of the teacher him or herself, this one needs to analyze his or her initial education, personal decisions or choices, and compromise to education and value of their job.

\section{Methodology}

Through a bibliographical research, books related to in-service education and scientific articles related to the Program of Educational Development of Paraná were read to elaborate the concepts of the theme.

According to a document available in the website of the State Secretariat for Education [7], in 2007 and 2008, 38 English teachers were advised by tutors of UEM. A questionnaire was applied to $55 \%$ of these teachers, who implemented the projects in public schools in Paraná, totalizing 21 teachers. The purpose of this questionnaire was to verify the continuity of the textbooks application after their training in the program, and their positive and negative aspects. The application was given as a probabilistic sample, allowing the generalization of 
the results to the total number arose. The items selection was done with the elaboration of a list of all the participant English teachers in Maringá, where the numbers were randomly selected, one by one, until the desired sample was complete, once "this sampling is chosen in a way that all the items of the sample have a known and equal probability of being selected" [8].

Because not all these teachers live in Maringá and their personal information was limited, they were reached on the internet, by email and Facebook, found by their full names available on their PDE projects description, avoiding that other people could answer to the questions.

Another questionnaire was applied to $77 \%$ of the tutors of UEM who advised the same PDE teachers in 2007 and 2008. According to the same document consulted to quantify the first sample, nine professors advised the participant teachers in the years mentioned previously, but only 7 of them answered to the questionnaire. This questionnaire was used in order to analyze the perspective of these tutors related to the capability of the participants referring to the development of a teaching proposal, specifically of the textbooks which were made.

The website of the State University of Maringá was accessed in order to verify the electronic address of the nine tutors and, thus, send the questionnaire and the aims of this work. The name of three of them was not found in the list of professors who work in the University, and the Department of English Language of UEM informed they were no longer part of it. Through a search on the internet and helpful information provided by one of the tutors, they were reached by email and the questionnaires were also sent to them.

The classification of the data collected through both questionnaires was made by simple tabulation, multiple answers tabulation and open questions tabulation, to make the analysis and data description possible, as well as their interpretation and evaluation. Both forms to collect data were structured questionnaires with open and closed questions, which decreased the interpretation errors and increased the trustworthiness of the collected data, being, thus, a qualiquantitative research. After presenting the data, the result was manifested through the final discussion. Among the scientific researches which involve PDE, there has not been developed any specific approach about the theme, having, thus, another relevant point for this analysis.

\section{The perspective of the teachers who participated in the Program of Educational Development of Paraná (PDE-PR)}

The first questionnaire was applied to 21 teachers, who implemented the projects in public schools in Paraná, in order to verify the continuity of the textbooks application after the training in the program, and their positive and negative aspects. The application was given as a probabilistic sample, allowing the generalization of the results to the total number arose.

Because not all these teachers live in Maringá and their personal information was limited, they were reached on the internet, by email and Facebook, found by their full names available on their PDE projects description, avoiding that other people could answer to the questions.

Most of the teachers showed a helpful attitude assisting the research and contacting other participants, but some emails were not replied, which made a second items selection necessary. Another list of participants was made and the numbers were again randomly selected, one by one, until the desired sample was completed.

All the 21 teachers classified the PDE program as being great for the public teachers' education, as well for their personal development. This result confirms the expectations of the State Secretariat for Education to improve the skills of these professionals while developing the program. These expectations are also observed in the questionnaire when all of them stated there was a significant difference in their teaching performance after their participation. This is because it was also expected that, having the opportunity to dedicate exclusively to their education, the teacher's effectiveness would be improved. The 21 teachers identified five common positive aspects of their participation in PDE: reevaluation of their personal and professional attitudes, improvement in their didactic production, positive results in the classroom, new attitude in the classroom, knowledge on new educational and scientific perspectives.

They also stated two negative aspects:

- Reality of school conditions x Professional aspiration, Impracticability of activities in state schools,

- The positive aspects demonstrate there is an intense and significant satisfaction of the teachers toward to research methodology and to contemporary issues related to their education.

During the program they take part into four courses and two seminaries, which has an amount of 
280 hours. These activities require extensive reading and reflection, mainly because they must perform theoretical and methodological articulations to elaborate their project and research. Also, the tutors of the University who advised them helped define and deepen their investigation, eliciting the necessity of describing their productions using a scientific language.

All of the participants complimented the role of the tutors who assisted them during the process of developing a pedagogical proposal. It shows that their advising and help are doubtlessly crucial to the process of development of the teacher's work, like in any other scientific production. It is also their duty to report the results of the program while the participants develop their teaching skills. This is the main concrete feedback the State Secretariat of Education receives to evaluate the evolution and production of the participant teachers. This point is discussed thoroughly in the next chapter of this work.

The negative aspects call the attention to a possible change to be made on the guidelines of the program. Teachers highlighted how impractical it is to apply the activities they develop and/or learn in the courses they are presented to during the program, which leads us to the thinking that the reality of the schools they work at is not the same reality the mentors of the PDE program perceive in Paraná. If the pedagogical proposal they elaborate is intended to be used in state schools, then the theoretical subsidies must be provided according to the great issues which are present in the state education. They must take into consideration not only the context of the school reality the PDE teachers belong to, but also its political, social and economical surroundings. Therefore, it is necessary to study and delineate the conditions and necessities of the state schools in order to understand the implications of executing the program.

Although the teachers have mentioned the impracticability of performing their proposals in the state schools they work at, a hundred percent of them have stated that most of the students had a positive response to the proposals and methods they created during PDE. There is, then, a contradiction while analyzing the data: if the teachers previously affirmed it is difficult - i.e. impracticable - to perform the activities they themselves developed during the PDE program, consequently, the students would not have a positive response to them and, thus, a different type of activity would have to be thought. Nevertheless, the questionnaire answers show another result. Hypotheses are preferred not to be arisen at this moment of the work for the analysis of the contradictory statements of the majority of the participants demands a deeper study that may be developed by the author in the future.
The teachers were also asked about the continuity of the projects developed by them and $71 \%$ affirmed their proposals are still being practiced in the schools they work at. The other $29 \%$ are retired. According to what was stated in the first chapter, the projects developed by these teachers aim a successful learning by students, and also the actual possibility of making them more compromised with the political and social processes of a fair society.

The establishment of these new practices is intended to be reached after the teachers' training and return to the classroom. Consequently, it is expected that, after only four years of the end of their participation, these teachers are still contributing to transform schools and value their careers. The results show that almost one third of the teachers who participated on PDE in 2007 and 2008 no longer work as a teacher.

The last question of the questionnaire asked teachers about their most important motivations to participate on the program:

- Knowledge

- Courses

- Rise in the career

- Renewing

- Students' needs

- Work suspension

Most of them stated that their three main motivations are to acquire knowledge, participate on the courses provided by the program and have a rise in their careers. Based on the guidelines of PDE/PR, the program was developed rightly to value the professionals of education, but also to consider the educational necessity of students and the condition of state schools. According to what the participant teachers answered, the students' needs are in the fifth position in the rank of their motivations to participate on the program.

\section{The perspective of the tutors of the State University of Maringá who advised teachers of the Program of Educational Development of Paraná (PDE-PR)}

Another questionnaire was applied to seven of the nine tutors of UEM who advised the 38 English teachers who participated in the PDE-PR in the years mentioned previously, in order to analyze their perspective related to the capability of the participants referring to the development of a teaching proposal, specifically of the textbooks which were made.

The website of the State University of Maringá was accessed in order to verify the electronic address of the nine tutors and, thus, send the questionnaire and the aims of this work. The name of three of them was 
not found in the list of professors who work in the University and the Department of English Language of UEM informed they were no longer part of it. Through a search on the internet and helpful information provided by one of the tutors, they were reached by email and the questionnaires were also sent to them. Of the nine tutors contacted, $77 \%$ of them replied, totalizing 7 answered questionnaires.

All the 7 tutors classified the PDE program as being great for the public teachers' education and stated that all the PDE teachers showed themselves committed to the program, and $71 \%$ of the tutors affirmed that the projects these teachers developed were considered good.

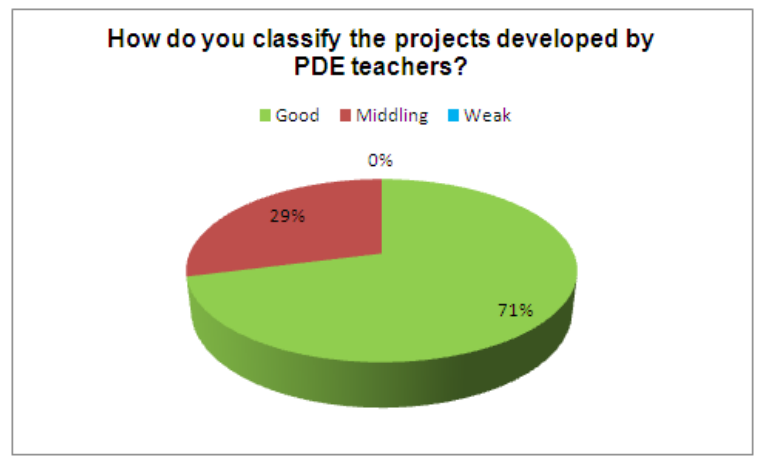

Chart 1. Perspective of UEM tutors on the projects developed by PDE teachers in 2007 and 2008

This result shows a small but considerable difference in the opinion of professors who advised PDE teachers, which may be justified with distinct degrees of personal and professional demands. The actual reasons which could lead us to a better conclusion would require a deeper study, but a reflection may be arisen analyzing the next point of the questionnaire.

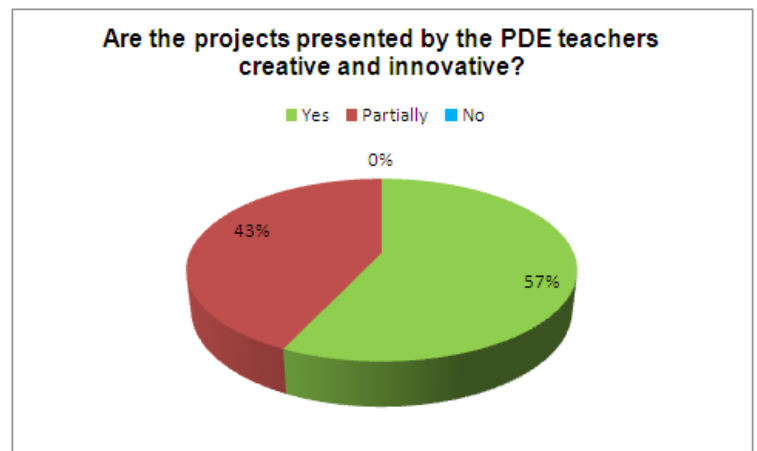

Chart 2. Perspective of UEM tutors on the creativity and innovation of the projects developed by PDE teachers in 2007 and 2008

When asked if the PDE teachers' proposals were developed with creativity and innovation, $43 \%$ of the tutors affirmed their projects were partially innovative and creative. In the first chart, $71 \%$ of the tutors considered the proposals developed by the
PDE teachers as good, but in the second chart, only $57 \%$ of them affirmed the same proposals were creative and innovative. Comparing the answers of these two questions, it may be stated that the result tends to be a little contradictory for a proposal which is first considered good and then considered only partially creative and innovative. Nevertheless, it may be once again justified with distinct degrees of personal and professional demands of the tutors, although there is a considerable difference on the opinion of the same enquiry. This difference also appears on the next question.

The tutors were asked if the PDE teachers were prepared to develop a pedagogical proposal, and only $28 \%$ of them had a positive answer.

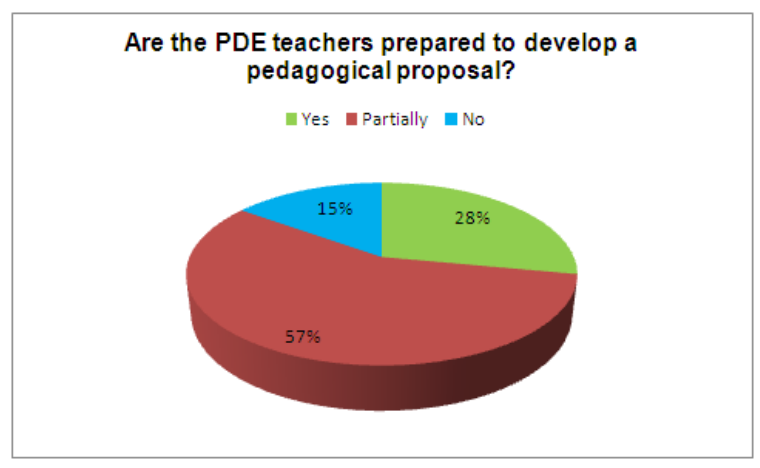

Chart 3. Perspective of UEM tutors on the preparation of the PDE teachers who developed their projects in 2007 and 2008

More than half of the tutors affirmed the PDE teachers were partially prepared to develop their projects, and $15 \%$ stated they had no preparation for it while participating on the program. This result leads us to the reflection that most of the teachers who apply for PDE-PR may lack some educational requirements which are crucial for the development of educational projects. These projects must be applied in public schools aiming an improvement on the reality in which students are being prepared for the future. Not only the gaps of this reality must be known, but also the gaps of teachers' education, in order to adapt the PDE program to actual needs.

To understand these gaps in the teacher's preparation, the tutors who showed a partial or negative answer to the previous question, were asked about the deficiencies they observed in the PDE teachers' performance while assisting them. They mentioned two points:

- Lack of linguistic knowledge;

- Lack of preparation to develop researches.

The tutors also indicated that their main motivation to apply for the program is a rise in their teaching career, having the students' necessity as less 
important. Based on this result it is possible to affirm that teachers are also a reflection of the educational gaps which exist in the educational system. These flaws may be present in public schools not only because of the challenges of the educational process, but also because there is the necessity to better prepare the individuals who develop students' formation, even before their participation on an inservice program like PDE.

\section{Conclusion}

When the performance of the teachers who participated in the PDE program was decided to be investigated, it became clear that the educational processes may only be understood when the meaning of policies are learned and teachers' practices are modified. In a political and pedagogical context, the innovations proposed to these teachers depend on the local conditions proposed by the system that schools are inserted in, which demands specific evaluations and interventions.

The guidelines of the Program of Educational Development involve a clear compromise of the teachers to establish new practices which could take students to a successful learning and, thus, the success of the teachers themselves. It is clear that new concepts of teaching are an alternative type of reorganization of relations established between students and teachers, but the evaluation of these procedures is crucial to analyze if these practices are truly effective.

To consider that a change proposal is incorporated to the teachers' personal repertoire, it has to be submitted to the time factor. And to comprehend the effects of the PDE program in the pedagogical practices of schools in Paraná after its realization, teachers who participated in 2007 and 2008 were questioned about their results and motivations.

Two questionnaires were applied to $55 \%$ of these teachers who implemented the projects in public schools in Paraná, and to $77 \%$ of the tutors of UEM who advised them, in order to verify the continuity of the textbooks application after their training in the program, and their positive and negative aspects.

All the 21 teachers who were investigated classified the PDE program as being great for the public teachers' education, as well for their personal development. But they also highlighted how impractical it is to apply the activities they develop during the program, which leads us to think that the reality of the schools they work at is not the same reality the mentors of the PDE program perceive in Paraná.

The results show that almost one third of the teachers who participated in PDE in 2007 and 2008 no longer work as a teacher; and that their main motivations to participate in PDE are related to their self improvement - personal and professional. Reinforcing that only teachers who are in Level II, Class 11 of the State Career Plan (Law 103/2004) may apply for the program, and that $29 \%$ of them are retired after only four years of the end of their participation, other Classes of teachers could be given the chance to be part of it, prioritizing the continuity of the proposals developed during the program.

What concerns one of the research questions of this study, which relates to the tutors' perspective related to the PDE teachers 'performance, all the 7 tutors classified the PDE program as being great for the public teachers' education, highlighting the commitment of all the PDE teachers during the program. Although most of the professors affirmed the projects developed were good, most of them also stated the same projects were partially innovative and creative. It leads us to the reflection that most of the teachers who apply for PDE-PR may lack some educational requirements which are crucial for the development of educational projects. The gaps pointed by the tutors involved lacks of linguistic knowledge and weak preparation to develop researches.

Another question, related to the continuity of the projects developed by the PDE teachers, they affirmed the practices are still permanent in the classes they teach, but only a deeper study could state the nuances of these pedagogical practices. One suggestion would be the modification or adaptation of these projects to the reality of the educational systems teachers and students are inserted in. It was mentioned the impracticability of applying the methods they learned in the program and once again the effectiveness of their work requires a more profound analysis.

The perspective of the tutors on these teachers constitutes aspects which had not been arisen in other academic studies and could lead to a thorough study to be made in the future by other authors.

\section{References}

[1] BOTTOS, Juliana. "A influência da mídia na desvalorização do professor da escola pública brasileira." Maringá - PR. Eduem, 2011.

[2] FALSARELLA, Ana Maria. "Formação continuada e prática de sala de aula: os efeitos da formação continuada na atuação do professor." Campinas - SP. Associated Authors, 2004.

[3] PARANÁ. Secretaria de Estado da Educação. "Uma nova Política de Formação Continuada e Valorização dos Professores da Educação Básica da Rede Pública Estadual - SynthesisDocument." 2007. Available in:

http://www.pde.pr.gov.br/arquivos/File/pdf/documento_sin tese.pdf, Accessed on: April the 19th, 2012. 
[4] ALMEIDA, Maria Isabel de. "Formação Contínua de Professores In: Formação Contínua de Professores", Boletim 13. Ministério da Educação. São Paulo - SP. Agosto, 2005. Available in:

http://tvbrasil.org.br/fotos/salto/series/150934FormaçãoCP rof.pdf. Accessed on: April the 20th, 2012.

[5] SILVA, Otto Henrique Martins da. "O Programa de Desenvolvimento Educacional do Paraná - PDE/PR.” IX Congresso Nacional de Educação - EDUCERE. III Encontro Sul Brasileiro de Psicopedagogia. Curitiba - PR. October, 2009. Available in:

<http://www.pucpr.br/eventos/educere/educere2009/anais/ pdf/2423_1687.pdf> Accessed on: April the 20th, 2012.

[6] SAVIANI, Dermeval. "PDE - Plano de Desenvolvimento da Educação: Análise crítica da política do MEC." Campinas, SP: Autores Associados, 2009.

[7]PDE-PR English teachers list, advised in 2007, available in http://www.diaadiaeducacao.pr.gov.br/portals/cadernospde /pdebusca/sinopses/14_lem.pdf; PDE-PR English teachers list, advised in 2008, available in http://diadiaeducacao.pr.gov.br/portals/cadernospde/pdebu sca/sinopses2008/lem_capa.pdf

[8] DENCKER, Ada de Freitas Maneti. "Pesquisa em turismo: planejamento, métodos e técnicas." São Paulo. Futura Publishing House, 1998. 